\title{
Hair Germ Model In Vitro via Human Postnatal Keratinocyte- Dermal Papilla Interactions: Impact of Hyaluronic Acid
}

\author{
Ekaterina Kalabusheva, ${ }^{1,2}$ Vasily Terskikh, ${ }^{1}$ and Ekaterina Vorotelyak ${ }^{1,2,3}$ \\ ${ }^{1}$ Laboratory of Cell Biology, N.K. Koltzov Institute of Developmental Biology, 26 Vavilov St., Moscow 119334, Russia \\ ${ }^{2}$ Department of Regenerative Medicine, Institute of Translational Medicine, Pirogov Russian National Research Medical University, \\ 1 Ostrovitianov St., Moscow 117997, Russia \\ ${ }^{3}$ Department of Cell Biology and Histology, Lomonosov Moscow State University, 1 Leninskiye Gory, Moscow 119234, Russia
}

Correspondence should be addressed to Ekaterina Kalabusheva; kalabusheva.e@gmail.com

Received 6 April 2017; Revised 27 June 2017; Accepted 19 July 2017; Published 10 October 2017

Academic Editor: Jaganmohan R. Jangamreddy

Copyright (C) 2017 Ekaterina Kalabusheva et al. This is an open access article distributed under the Creative Commons Attribution License, which permits unrestricted use, distribution, and reproduction in any medium, provided the original work is properly cited.

\begin{abstract}
Hair follicle (HF) reconstruction in vitro is a promising field in alopecia treatment and human HF development research. Here, we combined postnatal human dermal papilla (DP) cells and skin epidermal keratinocytes (KCs) in a hanging drop culture to develop an artificial HF germ. The method is based on DP cell hair-inducing properties and KC self-organization. We evaluated two protocols of aggregate assembling. Mixed HF germ-like structures demonstrated the initiation of epithelial-mesenchymal interaction, including WNT pathway activation and expression of follicular markers. We analyzed the influence of possible DP cell niche components including soluble factors and extracellular matrix (ECM) molecules in the process of the organoid assembling and growth. Our results demonstrated that soluble factors had little impact on HF germ generation and Ki67 ${ }^{+}$cell score inside the organoids although BMP6 and VD3 maintained effectively the DP identity in the monolayer culture. Aggrecan, biglycan, fibronectin, and hyaluronic acid (HA) significantly stimulated cell proliferation in DP cell monolayer culture without any effect on DP cell identity. Most of ECM compounds prevented the formation of cell aggregates while HA promoted the formation of larger organoids. In conclusion, our model could be suitable to study cell-cell and cell-niche interactions during HF reconstruction in vitro.
\end{abstract}

\section{Introduction}

Hair loss or alopecia is a widespread pathology; men and women at any age could be affected by any of the different types of alopecia. Several alopecia variants induce hair follicle (HF) miniaturization while others are associated with the complete loss of HF. Up to date, possible treatments include therapeutic agents (minoxidil, laser therapy, etc.) and surgical methods, including HF transplantation. One of the promising directions in HF research and treatment is reconstructing HFs from autologous cell source.

The growth and cycling activities of the HF are largely controlled by groups of epithelial and mesenchymal stem cells [1-3]. Epithelial stem cells give rise to progenitors which are the building blocks for HF morphogenesis during the hair cycle $[4,5]$. Mesenchymal stem cells of HF, located in a structure called dermal papilla (DP), have a unique ability to direct skin interfollicular keratinocytes (KCs) to the follicular lineage $[6,7]$.

DP cells maintain their inducing properties for several passages in culture, although the loss of contextual and positional cues from DP niche results in a rapid decline of their abilities that also involves the downregulation of specific markers [8-13]. DP niche components include at least soluble factors and extracellular matrix (ECM) molecules. Components of WNT and BMP signaling pathways are among the main players during the HF development and cycling. It was shown that HF germ keratinocytes express these molecules for the regulation of HF cycle [14]. These factors support and stimulate hair-inducing abilities of DP cells in vitro [10-13]. Besides hair-inducing abilities, the key feature of DP cells is a tendency to aggregate in culture 
reproducing the initial steps of $\mathrm{HF}$ formation. This process depends on ECM components, especially DP-specific protein versican [15]. Human HF development has not been well investigated, but basing on evidences obtained from rodent research, soluble factors mentioned above and other molecules are involved in the process of DP cell condensation. DP niche could be reconstructed using KCs to provide all the necessary soluble factors and $3 \mathrm{D}$ culturing to stimulate DP aggregation processes. DP cells in spheroid cultures partially restore the inductive capabilities as has been demonstrated in the recent research $[9,10]$. Combining DP cells and $\mathrm{KCs}$ in $3 \mathrm{D}$ environment resulted in the reconstruction of several essential epithelial-mesenchymal interactions typical for human HF $[16,17]$, although the optimal conditions allowing the complete HF follicle development from postnatal cells are still not being found.

Here, we developed two cultured HF germ models: coated and mixed aggregates. We evaluated the influence of DP cell identity on HF germ formation and expression of HF markers. Mixed aggregates appeared to be the most promising model. Lef1 expression confirmed WNT pathway activation. KCs switched to HF differentiation lineage demonstrating $\mathrm{P}$ cadherin expression. DP hair-inducing abilities correlated with the size and dividing cell ratio inside the aggregate. Soluble factors (BMP6, VD3, and VPA) maintained DP cell identity, while several ECM components (aggrecan, biglycan, fibronectin, and hyaluronic acid (HA)) significantly stimulated cell proliferation in 2D cultures. Nevertheless, only HA induced significant upregulation of the proliferation and increased the size of aggregates. Our results may provide the new in vitro method of HF development, and the model could be suitable to study cell-cell and cell-niche interactions during HF reconstruction in vitro.

\section{Materials and Methods}

2.1. Primary Cell Cultures. Human scalp biopsies were obtained after face-lift surgery from informed and consented patients aged 46 to 60 years from The Clinic of Active Longevity, Institute of Beauty on Arbat. Prior to cell isolation, skin samples were washed with Hank's solution (PanEko) with gentamicin.

DP cells were isolated by the technique developed by $\mathrm{Wu}$ et al. [18] and modified by Chermnykh et al. [19]. Briefly, the skin was incubated in $0.5 \%$ dispase (Gibco) at $4^{\circ} \mathrm{C}$ overnight. Subcutaneous fat was separated manually by surgical scissors and incubated in $0.2 \%$ collagenase type I (Gibco) for $2-3 \mathrm{~h}$ at $37^{\circ} \mathrm{C}$. After this step, HF bulbs were separated from fat by pipetting and centrifuging. To obtain DPs, HF bulbs were additionally incubated in $0.2 \%$ collagenase type I for $3-4 \mathrm{~h}$ at $37^{\circ} \mathrm{C}$. DPs were purified by a series of low speed centrifuge. The cells were cultured in AmnioMAX ${ }^{\mathrm{TM}}$-II medium (Gibco). Cells at passages 1-4 were used for all experiments if another one is not indicated.

The human lung fibroblasts (LF) were purchased from ATCC $\left(\right.$ ATCC $^{\circledR}$ CCL-204 $^{\mathrm{TM}}$ ) and cultured in AmnioMAXII medium.

For $\mathrm{KC}$ isolation, the epidermal layer was separated from the skin by incubation in dispase at $4^{\circ} \mathrm{C}$ overnight. The epidermal sheet was disrupted by trypsinization for $15 \mathrm{~min}$. KC suspension was inoculated in DMEM/F12 medium (PanEko) containing $4 \mathrm{mM}$ glutamine (Gibco), 10\% fetal bovine serum (FBS) (HyClone), $10 \mathrm{ng} / \mathrm{ml}$ EGF (Sigma Aldrich), $5 \mathrm{mg} / \mathrm{ml}$ insulin (Sigma Aldrich), and $0.25 \mathrm{mg} / \mathrm{ml}$ isoproterenol (Sigma Aldrich).

Overall, DP cultures obtained from 17 donors were used. Each DP culture was combined with 3-5 different donors of keratinocytes. Overall, 26 donors of keratinocytes were used. Each experiment was performed using DP from, at least, three donors. Results were compared in each pair of donors separately meaning that the control and the experiment group in each case were from the same donors of DP and keratinocytes. Results were considered to be valuable if they were reproduced in three DP cultures from different donors. All the cells obtained from KC and DP cultures were deposited in the Cell Culture Collection of the Institute of Developmental Biology, RAS.

2.2. Soluble Factors and ECM Molecules. The following soluble factors at designated concentrations were used in the study: bone morphogenetic factor 6 (BMP6, R\&D systems, $100 \mathrm{ng} /$ $\mathrm{ml}$ ), 1 $\alpha, 25$-dihydroxyvitamin D3 (VD3, Sigma Aldrich, $100 \mathrm{nM}$ ), valproic acid (VPA, Sigma Aldrich, $2 \mathrm{mM})$, Wnt3a (R\&D systems, $100 \mathrm{ng} / \mathrm{ml}$ ), Wnt5a (R\&D systems, $100 \mathrm{ng} /$ $\mathrm{ml}$ ), and Dickkopf1 (Dkk1, R\&D systems, $100 \mathrm{ng} / \mathrm{ml})$.

Among ECM components, we used aggrecan, biglycan, fibronectin, matrigel, collagen type I, hyaluronic acid (HA), and chondroitin sulphate A. Multiwell plates were coated with aggrecan (R\&D systems) at $0.4 \mathrm{nmol} / \mathrm{cm}^{2}$, biglycan (R\&D systems) at $0.2 \mathrm{nmol} / \mathrm{cm}^{2}$, fibronectin (R\&D systems) at $0.4 \mathrm{nmol} / \mathrm{cm}^{2}$, chondroitin sulphate A (CS) (Sigma Aldrich) at $0.05 \mathrm{mg} / \mathrm{cm}^{2}$, or $0.05 \mathrm{mg} / \mathrm{cm}^{2} \mathrm{HA}$ (Abcam, MW $1.6 \mathrm{kDa}$ ). Type I collagen solution extracted from the rat tail tendons was incubated at $37^{\circ} \mathrm{C}$ for $30 \mathrm{~min}$. Matrigel (BD Biosciences) was diluted at a concentration $0.12 \mathrm{mg} / \mathrm{cm}^{2}$ and incubated at $4^{\circ} \mathrm{C}$ overnight.

2.3. Lentiviral Transduction. Lentiviral constructions bearing red fluorescent protein TagRFP gene were provided by the Eurogene Company (Russia). DP cells at passage one and LF at passage 3 were transfected in serum-free AmnioMAXII medium with the addition of polybrene (Sigma Aldrich) with tenfold excess concentration of viral particles.

2.4. DP, LF, and KC Coculture. For monolayer culture, DP cells, labeled by RFP, and KCs were trypsinized, mixed in $1: 1$ proportion, seeded in a 48 -well plate (Corning) at a concentration of $10^{5}$ cells per well in DMEM medium (PanEko) containing $4 \mathrm{mM}$ glutamine and 10\% FBS, and cultured for three days.

To obtain mixed aggregates, DP cells or LF, labeled by RFP, and KCs were mixed in 1:1 proportion and cultured in a hanging drop in DMEM medium containing $4 \mathrm{mM}$ glutamine and $10 \%$ FBS at a concentration of $7 \times 10^{3}$ cells per aggregate. Cells were cultured for 3 to 14 days. To assess the influence of soluble factors and ECM molecules on aggregate generation, BMP6, VD3, VPA, Wnt3a, Wnt5a, Dkk1, aggrecan $(0.4 \mu \mathrm{M})$, biglycan $(0.2 \mu \mathrm{M})$, fibronectin $(0.4 \mu \mathrm{M})$, 
TABLE 1: Primers for real-time polymerase chain reaction.

\begin{tabular}{lcc}
\hline Target & \multicolumn{1}{c}{ Forward primer } & Reverse primer \\
\hline hHPRT & ACCAGGTTATGACCTTGATT & AAGTTGGCCTAGTTTATGTT \\
ALP & GCACCTGCCTTACTAACTCC & AACATAGACACTGCCCTCATC \\
Versican & TCCAACAGGAAAGGAATGAA & TTACTGGGGACAGTGAGGTG \\
WNT5a & GGGTGATGCAGATAGGTAGG & TCAGGTGTAGGGACAGGAAT \\
LEF1 & TGAAGGTGATTCTTGGGTTAT & CACGGGCACTTTATTTGACT \\
$\beta$ Catenin & CAGCAGCAATTTGTGGTAGG & TAGCTCTTCAGGAAGACGGA \\
P cadherin & CACATCTGGGTTAAGGAGTT & CAGGAGAAGGCACAGTCGTA \\
EpCAM & CAGCGGTTCTTTTGGCATAC & TCCCCATTTACTGTCAGGTC \\
EDAR & TTGCCTCCTTTCTACTGTTGC & GCTTACCTTCCACGACTCCA \\
TCHH & CTCCTTGAAAGGGAATTTGG & TTCCTTGCTCTGGTCTCCTC \\
Keratin 75 & TCAAAGTCAGGTAAGTGGGAGA & CAAGATGAAGGTCCTTGTGCT \\
Keratin 35 & TGCCCTGACTACCAGTCCTA & TCCAAAGCCACTCTGAACCT \\
Keratin 32 & CATTTCAGGACCATTGAGGA & AGTCCAGTTCCCTTCCCAGA \\
\hline
\end{tabular}

CS $(0.5 \mathrm{mg} / \mathrm{ml}), 1.12 \mathrm{mg} / \mathrm{ml}$ matrigel and collagen I at a dilution $1: 10$, and $0.5 \mathrm{mg} / \mathrm{ml} \mathrm{HA}$ were added to cell suspension prior to the cell aggregation.

To obtain coated aggregates, DP cell suspension, labeled by RFP, was placed in a hanging drop at a concentration of $3.5 \times 10^{3}$ cells per aggregate in DMEM medium containing $4 \mathrm{mM}$ glutamine and 10\% FBS. After three days in culture, aggregates were transferred to preliminarily prepared hanging drops containing $3.5 \times 10^{3}$ keratinocytes and then additionally cultured for 3 to 14 days.

2.5. Alkaline Phosphatase Staining. DP cells were fixed in $70 \%$ ethanol for $15 \mathrm{~min}$ at room temperature and then washed with phosphate saline buffer (PBS) pH 7.5 (Gibco). Cultures were incubated in NBT/BCIP solution (Roche) for $30 \mathrm{~min}$ at room temperature protected from light. Samples were analyzed using an Olympus IX51 fluorescent microscope equipped with an Olympus DP70 camera.

2.6. Immunocytochemistry. The monolayer cultures were fixed in 4\% paraformaldehyde (PFA) (Riedel-de Haen) for $15 \mathrm{~min}$ at room temperature and then washed with phosphate saline buffer (PBS) pH 7.5 (Gibco). Primary antibodies anti-Ki67 (Abcam, ab16667) and anti-versican (R\&D systems, AF3054) were diluted in 1:50 and 1:20, respectively, in permeabilization buffer consisting of PBS, with addition of 1\% Triton X-100 (AppliChem), 1\% Tween 20 (AppliChem), 0.5\% bovine serum albumin (Sigma Aldrich), and sodium azide (Sigma Aldrich). Samples were incubated at $4^{\circ} \mathrm{C}$ overnight and then washed with PBS for one hour. Secondary anti-rabbit IgG Alexa fluor 488 antibodies (Life technologies, A21206) and anti-goat IgG Alexa Fluor-488 (Life technologies, A21467) were diluted in PBS in 1:500 and incubated with the samples for $1 \mathrm{~h}$ at room temperature. DAPI (Biotium) was used for nucleus staining at a concentration of $1 \mathrm{mg} / \mathrm{ml}$. Samples were analyzed using a fluorescent microscope (IX51, Olympus) equipped with a DP70 camera.

Aggregates were fixed in $4 \%$ PFA for $45 \mathrm{~min}$ at room temperature and incubated in permeabilization buffer for $1 \mathrm{~h}$. The following primary antibodies were used: anti-Ki67,
anti-Lef1 (Santa Cruz, sc-8591) diluted in 1:200, anti-P cadherin $(\mathrm{R} \& \mathrm{D}, \mathrm{AF} 960)$ diluted in $1: 20$, and anti-EpCam $(\mathrm{R} \& \mathrm{D}$, MAB861) diluted in 1:15. Then, samples were processed as indicated above. Toto-3 (Life technologies) was used for nucleus staining at a dilution of $1: 300$ in Tris- $\mathrm{HCl}$ buffer (Helicon) with RNase (Fermentas) pretreatment, or alternatively, DRAQ5 (Life technologies) was used at a dilution of $1: 1000$ in PBS. Samples were mounted in fructose and analyzed using a confocal microscope (Leika SP5, Germany).

2.7. Gene Expression Analysis Using the qRT-PCR Method. RT-qPCR was used to quantify the mRNA expression of ALP, Versican, WNT5a, LEF1, $\beta$ catenin, $\mathrm{P}$ cadherin, EpCAM, TCHH, Keratin 75, Keratin 35, and Keratin 32. RNA was isolated from each group by using RNAzol reagent (MRC) according to the manufacturer's instructions. Firststrand cDNA was synthesized using a QuantiTect Reverse Transcription Kit (Qiagen) according to the manufacturer's instructions. qPCR was performed in triplicate using a CFX96 Real-Time PCR system (Bio-Rad Laboratories) under the following conditions: $10 \mathrm{~min}$ at $95^{\circ} \mathrm{C}$, followed by 45 cycles of $15 \mathrm{sec}$ at $95^{\circ} \mathrm{C}$, and $1 \mathrm{~min}$ at $60^{\circ} \mathrm{C}$ for qPCR amplification. The reaction was performed in a total volume of $25 \mu \mathrm{l}$, containing $5 \mu \mathrm{l}$ SYBR Low Rox Master Mix (Eurogen), $1 \mu \mathrm{l}$ cDNA, $0.5 \mu \mathrm{l}$ each primer, and $18 \mu \mathrm{l}$ sterile distilled water. Target gene concentration was calculated using calibration curve and normalized to the level of HPRT. The primers used are indicated in Table 1.

2.8. Imaging, Analyzing, and Statistics. The fluorescent images of the monolayer cultures were analyzed automatically to define the ratio of actively proliferating cells depending on the ECM or the soluble factor used with the particular culture. The assay was carried out using the CellProfiler version 2.2.0 software. The share of proliferating cells in a monolayer was identified as the ratio of Ki67-positive cell nuclei to the total number of cell nuclei in the picture. From 30 to 50 , images of each sample taken with 20x magnification were used for this analysis. 
To evaluate the proliferation ratio in mixed aggregates, nuclei were counted on $\mathrm{z}$ stacks from confocal imaging using ImageJ.

Statistica 8 was used for the statistical analysis. Data are shown as a mean \pm standard error of the mean and represent the average of three separate experiments. The Mann-Whitney $U$ test was used to determine the statistical significance of observed differences at the level of $p \leq 0.05$.

\section{Results and Discussion}

3.1. General Characteristics of the DP-KC Aggregates. In mixed aggregates (prepared as it is designated in Materials and Methods), spontaneous cell sorting occurred. DP cells interacted with each other and produced spheroid structures while KCs tended to form extended trabeculae. The length of trabeculae varied among donors. These epithelial structures were somewhat similar to the tubules grown in the collagen gel in the presence of DP or conditioned medium [19]. In the course of aggregate preparation, $\mathrm{KC}$ trabeculae embedded into DP spheroids: several trabeculae might be embedded into one DP spheroid, while one trabecula could bear several DP aggregates. In rare cases, DP cells made a belt surrounding KC trabeculae (Figure 1(a)). The borderline between DP cells and KCs could be well distinguished. We did not observe any DP cells penetrating KC trabeculae. Single KCs were found inside DP cell aggregates (Figure 1(b)). Proliferating $\mathrm{Ki}^{+} 7^{+} \mathrm{KCs}$ were found exclusively at the borderline between DP cells and KCs (Figure 2(a)). KCs maintained proliferation at least for 5 days. Proliferative DP cells were detected throughout the aggregates. We analyzed the expression of early HF marker Lef1 and found that proliferative KCs at the site of epithelial-mesenchymal contact were positive for this marker (Figure 2(a)). Lef1 expression in DP cells was irregular and was not restricted to any specific zone (data not shown).

To obtain coated aggregates, DP cell spheroids were transferred into suspension of KCs, which then attached to the spheroid surface (Figures 1(a) and 1(c)). We noticed that DP cells formed processes and sometimes migrated into the KC layers that resulted in the border between DP spheroid, and KCs became indistinct (Figure 1(c)).

We did not identify any $\mathrm{Ki}^{+}$nuclei among $\mathrm{KCs}$ in coated aggregates. DP cells behaved differently: they proliferated and migrated through the KC layers (Figure 2(b)). In coated aggregates, KCs and DP cells were negative for Lef1 (Figure 2(b)). The system of coated aggregates did not support epidermal proliferation: KCs attached to the DP spheroid surface completely exfoliated after 5-10 days.

Lef1 expression and $\mathrm{KC}$ proliferation indicated that mixed aggregates demonstrated epithelial-mesenchymal interaction, similar in some aspects to that in HFs. We analyzed aggregates for the markers of human HF placode $P$ cadherin and EpCAM [20] and found their expression in KCs inside mixed aggregates (Figure 2(a)). We did not observe $\mathrm{P}$ cadherin expression in coated aggregates, while KCs were positive for EpCam (Figure 2(b)). P cadherin expression indicates the onset of neofolliculogenesis, since this protein is expressed not only during the development of HFs but also in HF cycling [21]. P cadherin expression was observed in regenerated HFs induced by DP cell transplantation [22]. EpCam was found to be expressed in early HF placodes of 11-12 week human fetus and seems to be the sign of the earliest steps of HF morphogenesis [20].

Both types of aggregates were cultured up to 14 days; however, we did not observe any changes in morphology indicating further development of HFs. Basing on aggregate characteristics, we discarded coated aggregates from our further study.

We confirmed the specificity of HF marker expression using LF instead of DP cells in mixed aggregates. LF were chosen to avoid the possible contamination of skin fibroblast culture with DP cells and to avoid the nonspecific expression of markers. Mixed aggregates with LF did not correspond to those with DP cells: fibroblasts attached as small clusters on the surface of KC spheroids (Figure 1(c)). Neither KCs nor LF were positive for Lef1 or Ki67. P cadherin expression was absent while EpCam expression was observed (Figure 2(c)). The results provide evidence that the process of HF morphogenesis in mixed aggregates is induced by DP cells, and Lef1 and P cadherin are the specific markers of an onset of this process. In our hands, EpCAM staining could not be used as a reliable marker of folliculogenesis as weak staining for this marker was found in control experiments with LF and even in monolayer KCs (data not shown).

DP cells and KC suspension are able to self-organize and form mature $\mathrm{HF}$ after subcutaneous cotransplantation into immunodeficient mice $[23,24]$. Fetal cells have a potential to reaggregate and develop to the HF-like structures which are suitable for transplantations [25-27], while adult cells lose these abilities. Similarly, the use of embryonic cell and bioprinting technologies allows the establishment of tooth primordia which are capable to replace adult teeth $[28,29]$, although postnatal cells are ineffective in tooth regeneration [30]. Here, we demonstrate that postnatal cells are able to self-organize and to reproduce initial steps to form hair germ-like structures.

The inability of coated aggregates to reproduce $\mathrm{HF}$ epithelial-mesenchymal interactions highlights the significance of self-organization processes which take place during the arrangement of mixed aggregates. Epithelial cells from other organs have been demonstrated to exhibit high self-organization abilities under 3D conditions [31-33]. Our results have revealed that the presence of DP cells is sufficient for proper $\mathrm{KC}$ self-organization in hanging drops when used as a single-cell suspension. Yen and coauthors [34] have obtained HF organoids using lowadhesive conditions. A structure of these organoids was similar to our coated aggregates; nevertheless, key features of folliculogenesis onset were observed which is in contradiction with our results. These aggregates were obtained using cell culture conditions, which supported the selfaggregation and self-organization. In other words, cells managed the process of spheroid formation by themselves as well as in our mixed aggregates; the difference in final organoid structure is explained by different forces which stimulated the process of aggregation: gravitation or specified adhesiveness. 


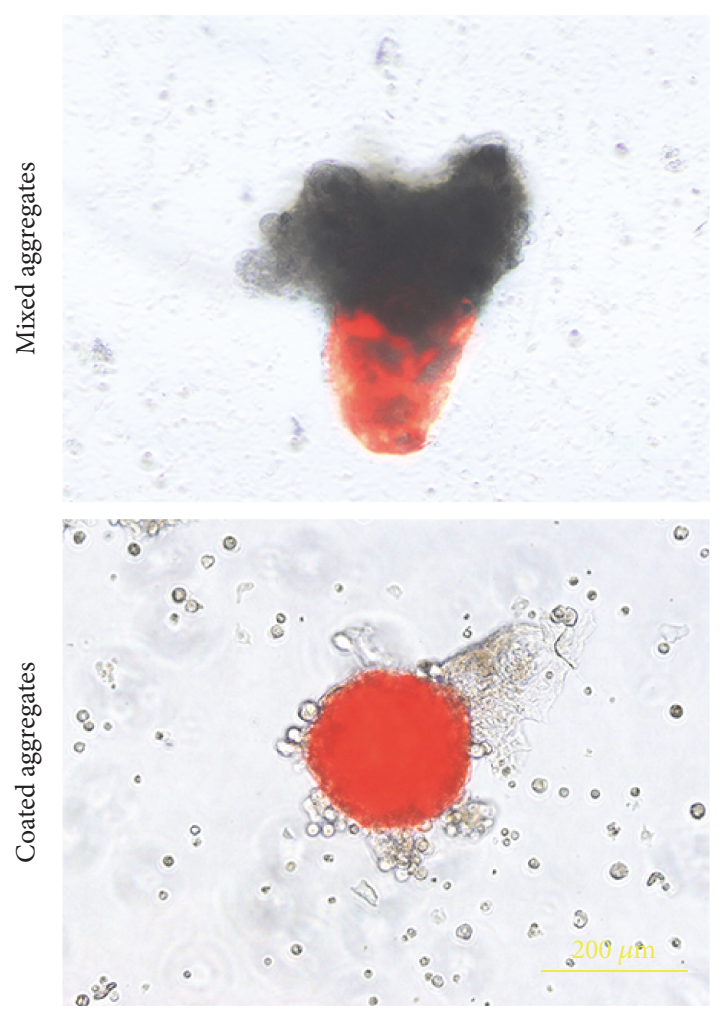

(a)
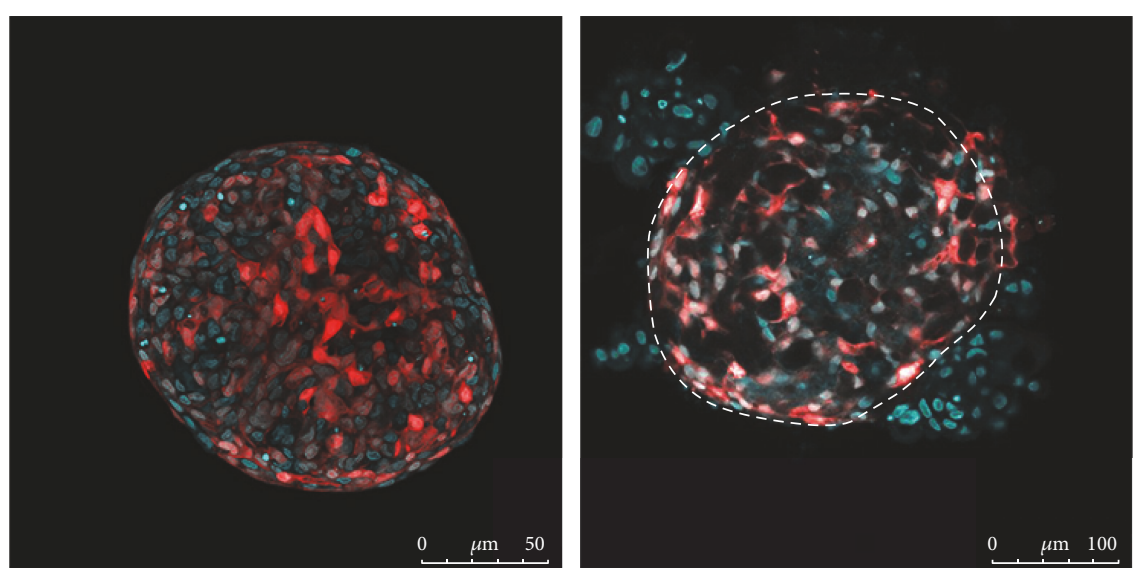

(c)
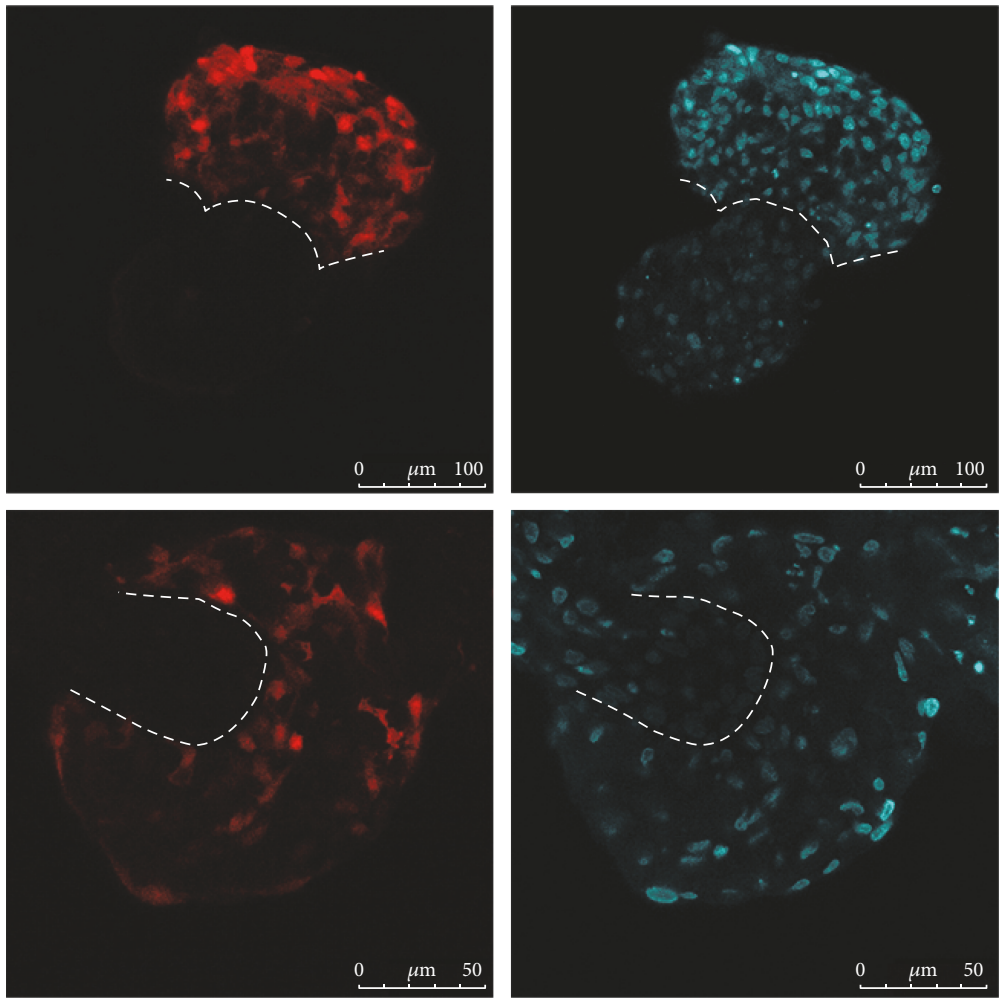

(b)

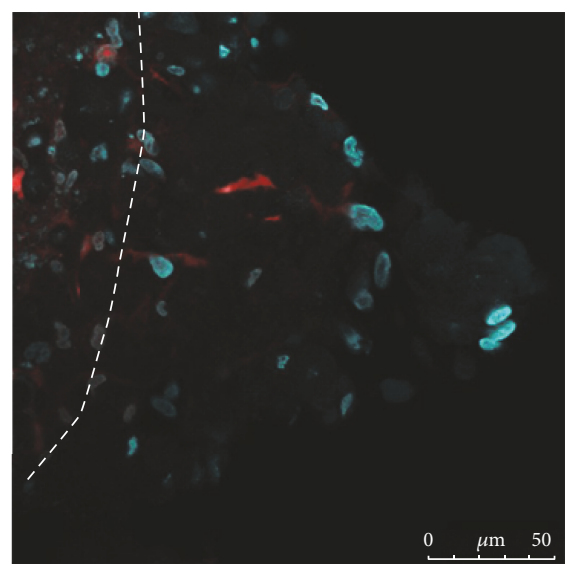

$\mu \mathrm{m} \quad 50$

Figure 1: Aggregate morphology. (a) Mixed and coated aggregates. Fluorescent and light microscopy. Scale bar $200 \mu \mathrm{m}$. (b) Mixed aggregate structure. Confocal microscopy. Scale bar $100 \mu \mathrm{m}$ for upper row; scale bar $50 \mu \mathrm{m}$ for bottom row. (c) Coated aggregate morphology. Left image is DP spheroid before coating, and middle and right images are coated aggregates. Dashed lines show the borderline between DP aggregate and KCs. Confocal microscopy. Scale bar $50 \mu \mathrm{m}$ for left and right image and scale bar $100 \mu \mathrm{m}$ for middle image. DP cells are labelled with RFP. Nuclei are counterstained with TOTO3 (cyan color). Dashed lines show the borderline between DP cells and KCs.

3.2. Expression of Specific Markers of DP Cells and Folliculogenesis in Different Types of DP-KC Aggregates. We further evaluated the difference between mixed and coated aggregates by analyzing the gene expression of DP and HF epithelial markers (Figure 3). Mixed aggregates showed increased expression of such DP markers as versican and Wnt5a while coated ones demonstrated a high level of alkaline phosphatase (ALP). An elevated level of Lef1 in mixed aggregates confirmed the initiation of folliculogenesis while increased $\beta$ catenin expression was found in coated aggregates. Several markers of folliculogenesis including $P$ cadherin and $K 75$ were upregulated in mixed aggregates. These results confirm the onset of morphogenetic processes in mixed aggregates. The increase in the expression of DP markers in coated aggregates may be accounted for the extended period of DP cell cultivation in this case as preliminary prepared DP aggregates have been used in this variant of aggregates. Prolonged cultivation of DP cells in spheres upregulates the expression of specific DP genes. 

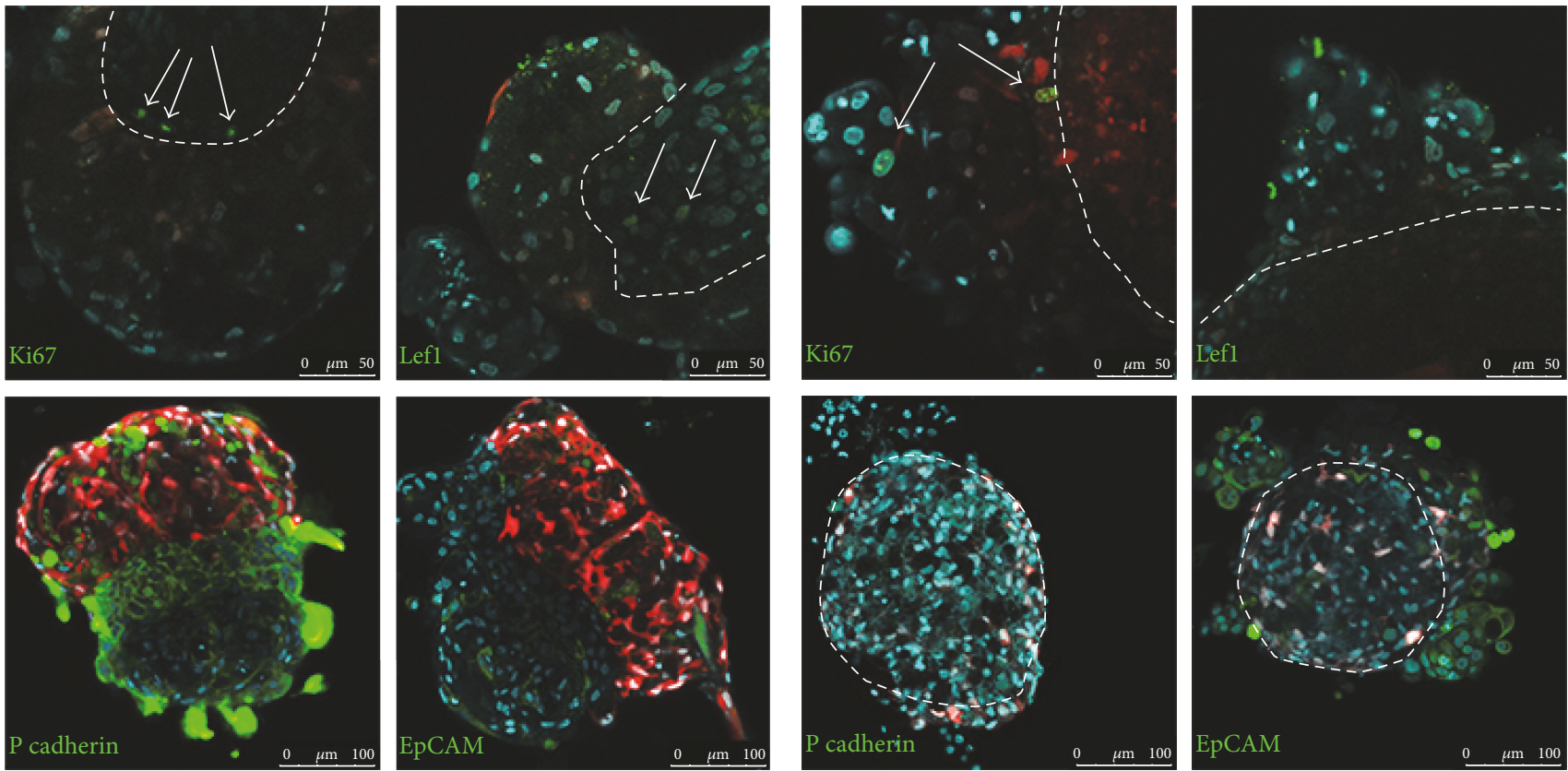

(a)

(b)
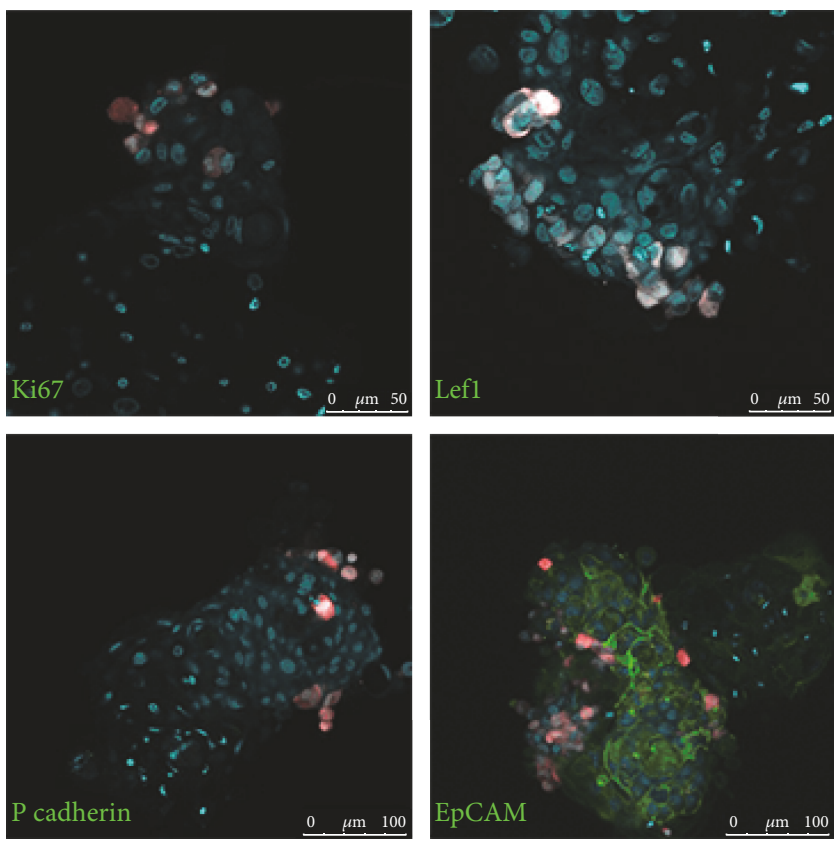

(c)

FIGURE 2: Cell proliferation and HF marker expression in aggregates: (a) mixed DP-KC aggregates; (b) coated DP-KC aggregates; and (c) LF-KC mixed aggregates as a control. Confocal microscopy. DP cells and LF are labelled with RFP. Immunocytochemistry for Ki67, $\mathrm{P}$ cadherin, Lef1, and EpCAM as indicated (green). White arrows point to Lef1 and Ki67 positive nuclei; white dotted lines show the borderline between DP cells and KCs. Nuclei are counterstained with TOTO3 or DRAQ5 (cyan color). Scale bar $50 \mu \mathrm{m}$ for Ki67 and Lef1 staining and $100 \mu \mathrm{m}$ for P cadherin and EpCAM staining. Dashed lines show the borderline between initial DP aggregate and KCs.

3.3. Monolayer Modeling of DP-KC Interaction. To clarify the interaction between two cell types within aggregates, we imitated the interaction between DP cells and KCs in aggregates with monolayered coculture. We mixed DP cells and KC suspension and cultured it on the adhesive surface. After 3 days, DP cells formed confluent monolayer, keratinocytes adhered as separate clumps, several clumps resided atop of the DP cells monolayer, and others were located on the plastic and surrounded by DP cells (Figure 4(a)).

We observed high proliferation level in the $\mathrm{KC}$ clumps located on the bottom of a culture dish. KC clumps atop of DP cells comprised few Ki67 ${ }^{+}$cells. We also observed DP cells, which had contacted with these clumps and formed processes inside KC sheet. The contact with DP cells 
ALP

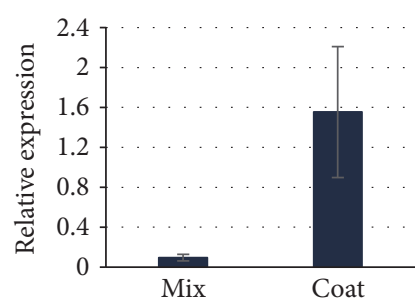

$\beta$ catenin

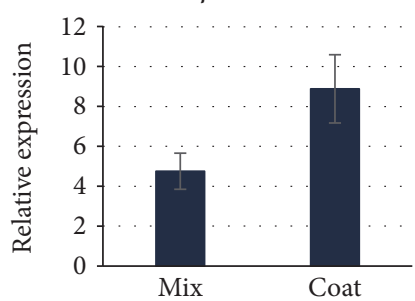

$\mathrm{TCHH}$

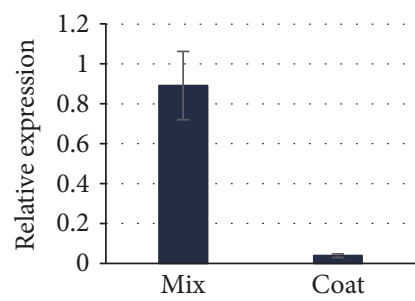

VERSICAN

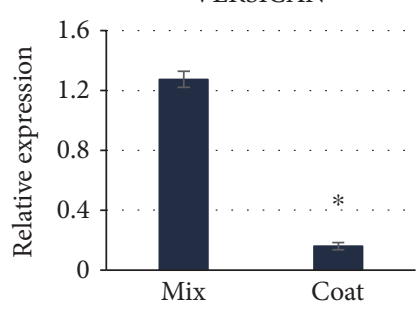

$\mathrm{P}$ cadherin

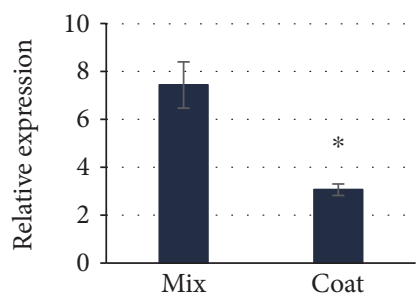

K75

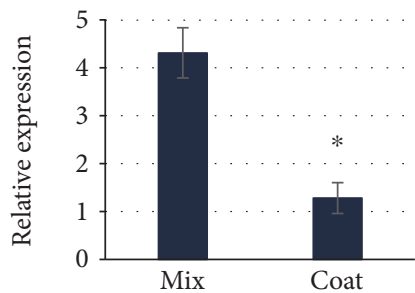

WNT5a

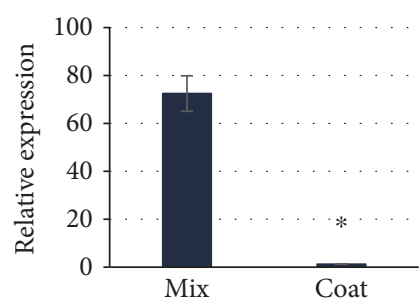

EpCAM

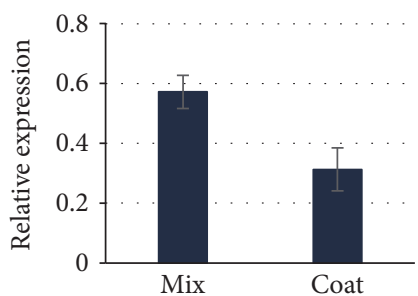

K32

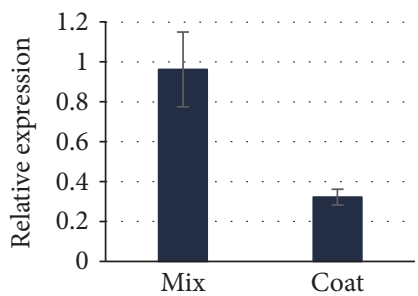

LEF1

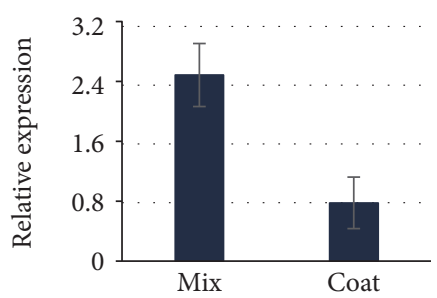

EDAR

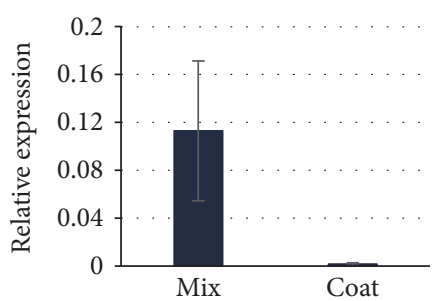

K35

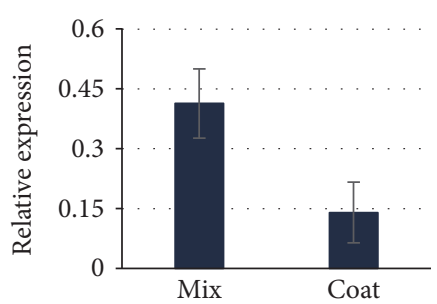

FIGURE 3: Relative expression of DP and folliculogenesis markers studied with RT-qPCR. Expression level of each gene was normalized to HPRT. * $p<0.05$, Mann-Whitney $U$ test.
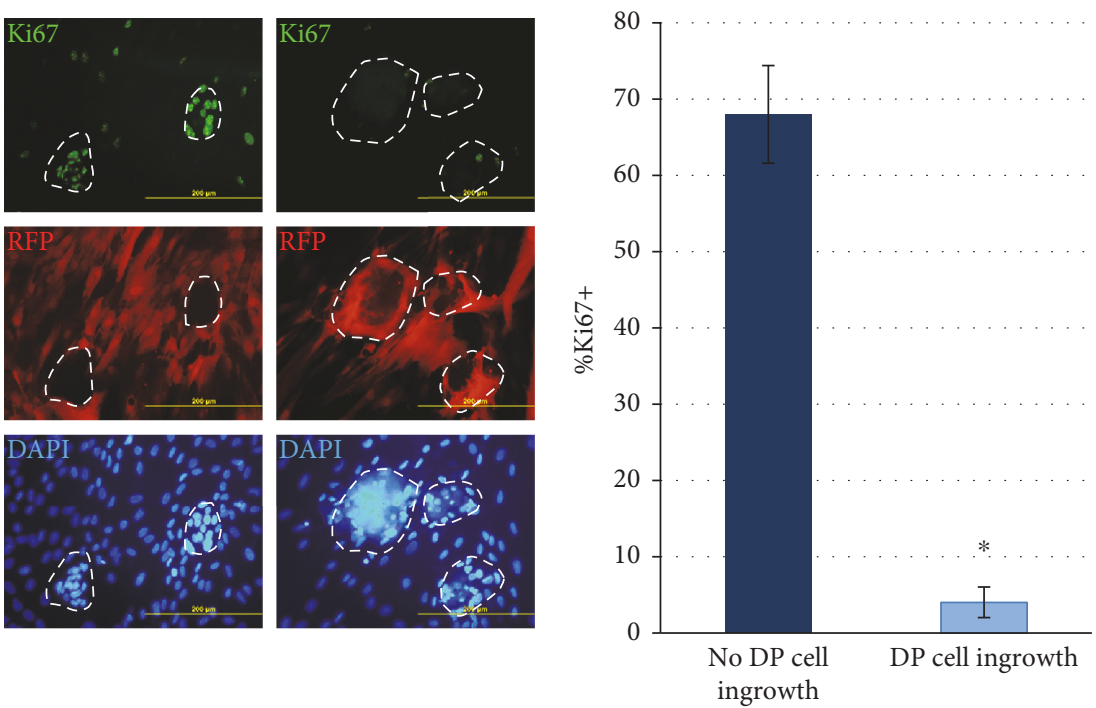

(a)

(b)

Figure 4: (a) KC proliferation in monolayer coculture with (right column) and without (left column) the contact/ingrowth of DP cells. DP cells are labelled with RFP. Nuclei are counterstained with DAPI. Scale bar is $200 \mu \mathrm{m}$. Fluorescent microscopy. (b) KC proliferation rate in clumps depending on DP cell contact/ingrowth. ${ }^{*} p<0.05$, Mann-Whitney $U$ test.

appeared to reduce the number of $\mathrm{Ki}^{+} 7^{+} \mathrm{KCs}$ more than 10 times (Figure 4(b)). The results demonstrate that close contact of DP cells with $\mathrm{KC}$ layers inhibits the proliferation of
KCs. It corresponds to the absence of KC proliferation in coated aggregates. Thus, this was not exclusively the attribute of $3 \mathrm{D}$ culture, and the pattern of mutual influence between 

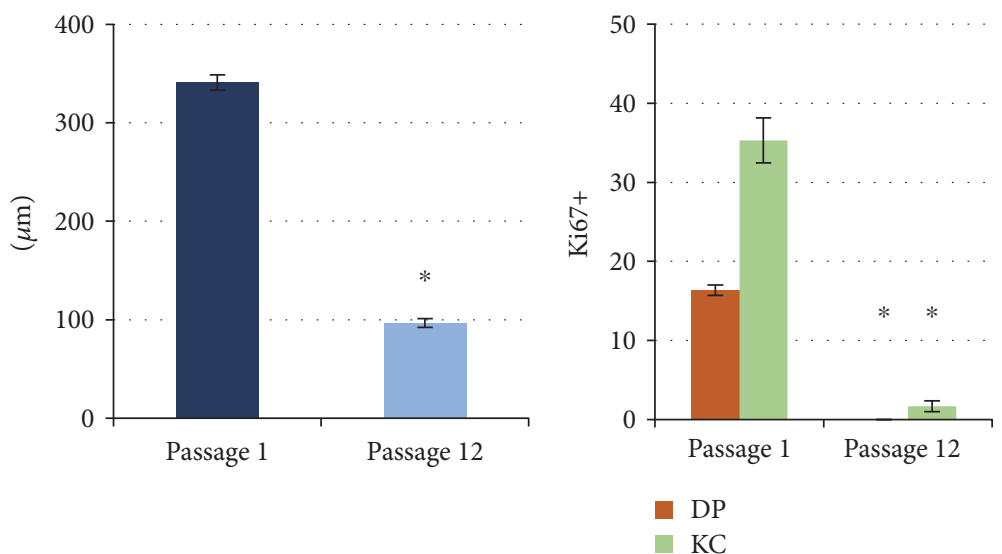

(a)

(b)
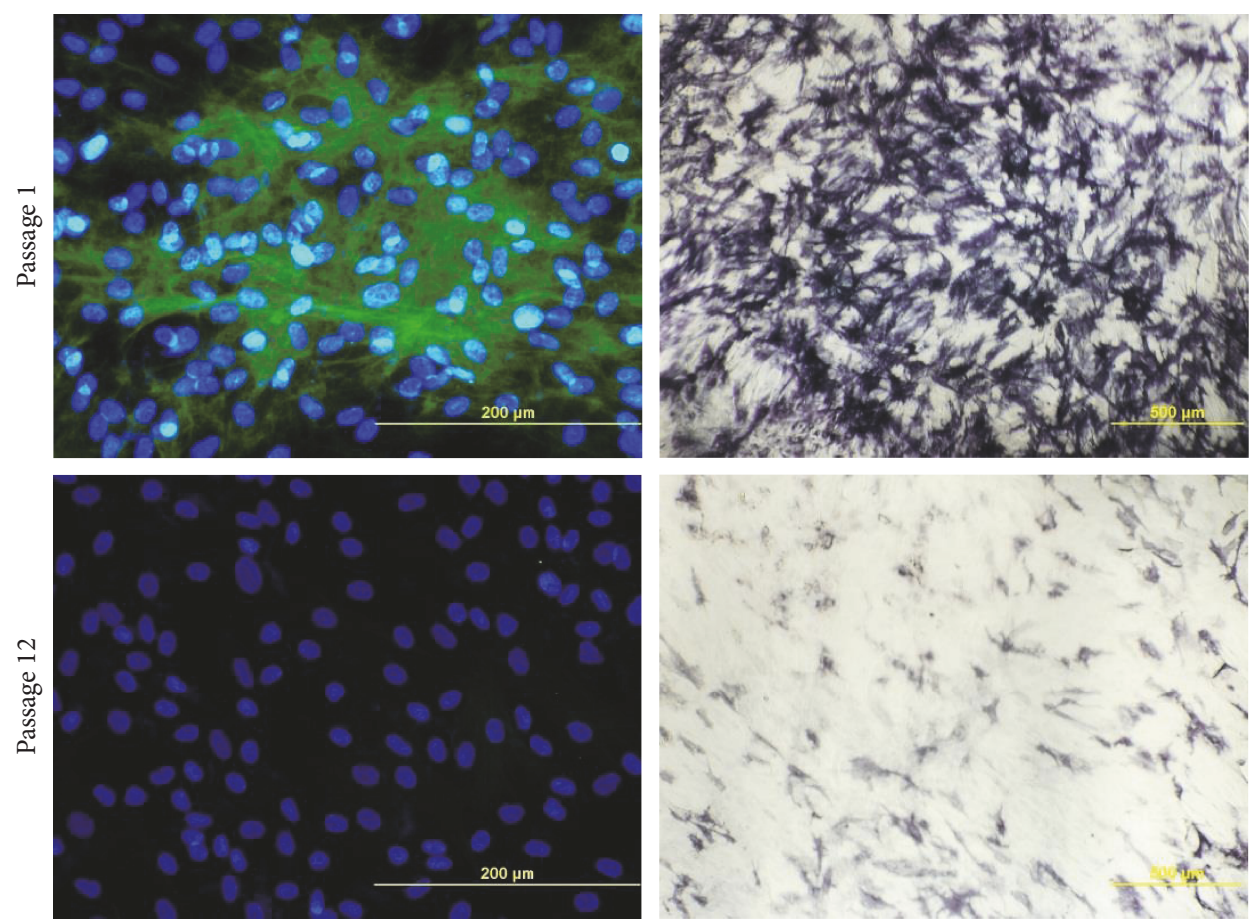

(c)

Figure 5: (a) The size of mixed aggregates with DP cells of passages 1 and 12. (b) The number of Ki67 ${ }^{+}$nuclei in DP cells and KCs in mixed aggregates per one aggregate generated with DP cells of passages 1 and 12. (c) Versican and ALP expression cultures of DP cells of passages 1 and 12. Versican: immunocytochemistry, fluorescent microscopy, scale bare $200 \mu \mathrm{m}$. ALP: histochemistry, bright field microscopy, scale bare $500 \mu \mathrm{m} .{ }^{*} p<0.05$, Mann-Whitney $U$ test.

DP cells and KCs in coated aggregates is similar to that in the monolayer culture reflecting some basic mode of interaction. Noteworthy, DP represents a highly adhesive structure comprising tightly bounded cells, which rarely escape DP. The only way of migration in natural niche is migration into connective tissue sheath. In this situation, KCs of the matrix never contact DP cells. In case of skin and HF damage, rapid migration of DP cells may cause $\mathrm{KC}$ elimination from the damaged site.

3.4. DP Cell Identity Influences the Size of Aggregates and Cell Proliferation. DP cells are distinguishable from other skin cell types by their ability to induce HF formation after transplantation into the skin $[6,7]$. In vivo DP cells interact with $\mathrm{HF}$ $\mathrm{KCs}$, and these interactions promote $\mathrm{HF}$ cycle [1-3]. In culture, DP cells lack their niche essential compounds that results in quick loss of hair-inducing abilities upon passaging [8-13].

We evaluated the impact of DP identity on hair germ generation using DP cells of passages one and 12. The decrease of hair-inducing abilities was manifested by the drop in ALP and versican expression (Figure 5(c)). Low DP hair-inducing abilities (passage 12) resulted in smaller aggregates. Aggregates containing DP cells from the first passage 

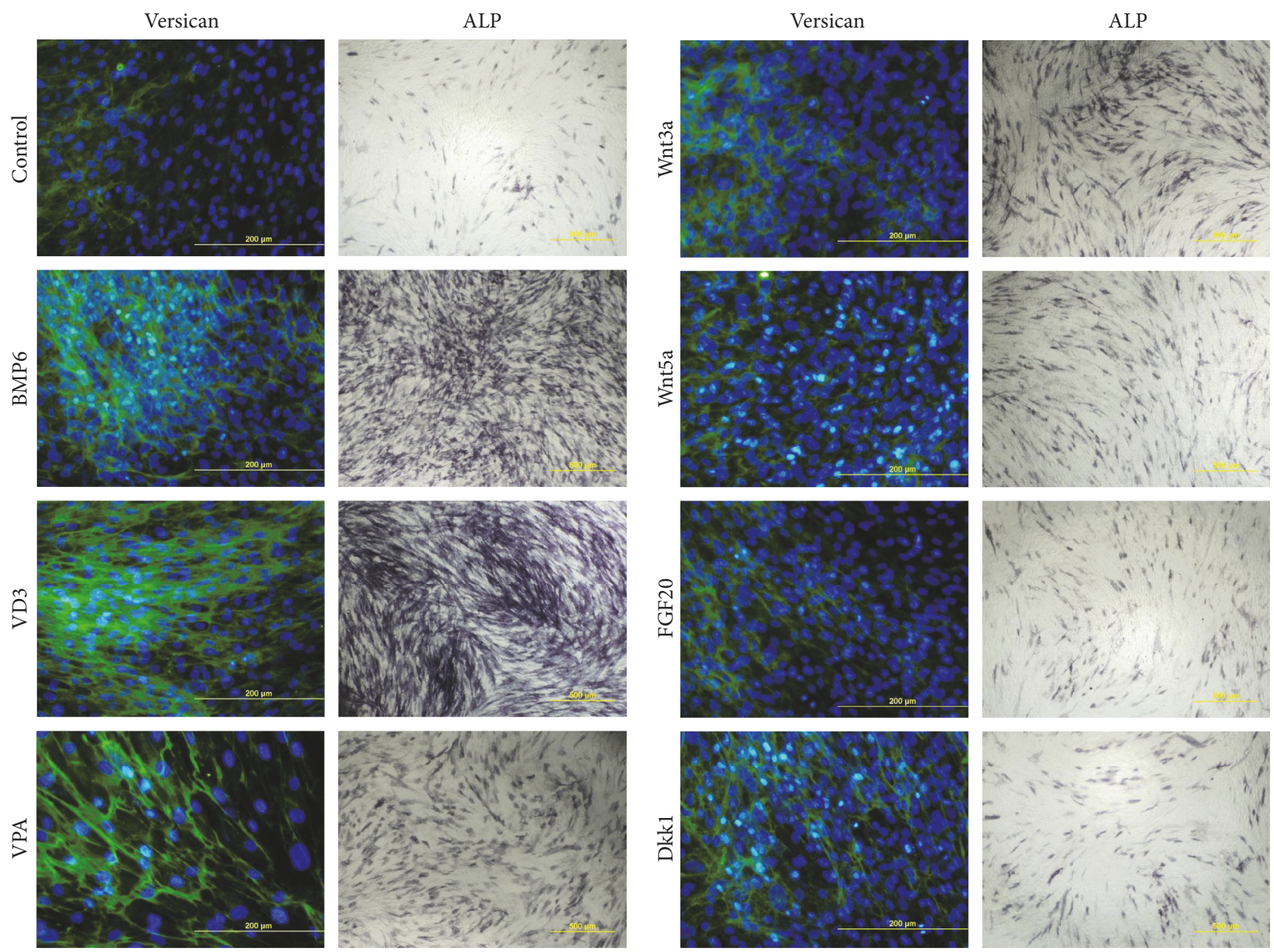

FiguRE 6: Versican and ALP expression in the presence of soluble factors. Versican: immunocytochemistry, fluorescent microscopy, scale bare $200 \mu \mathrm{m}$. ALP: histochemistry, bright field microscopy, scale bare $500 \mu \mathrm{m}$.

were three times bigger than those made of cells from passage 12 (Figure 5(a)). The reason for size diminishment was the inability of passage $12 \mathrm{DP}$ cells to produce single aggregate per one hanging drop. Instead, they formed 5-6 separate small aggregates per one drop.

HF marker expression was not affected (data not shown) whereas the number of Ki $67^{+}$cells was dramatically decreased in aggregates with late passage DP cells (Figure 5(b)). Therefore, the downregulation of DP hair-inducing abilities resulted in inability to form aggregates properly and to stimulate KC proliferation.

3.5. Impact of Soluble Factors and ECM Components on DP Identity. Previous studies reported various approaches to maintain intrinsic characteristics in cultured DP cells, including the addition of certain soluble factors [10-13] and ECM compounds [35]. Since high hair-inducing abilities of DP cells are important for the aggregate formation and KC proliferation level maintaining, we tried to utilize this approach in order to improve the quality of DP cell monolayer culture before the generation of DP-KC aggregates and subsequently to facilitate aggregate acquisition.

Bioinformatics analysis revealed the involvement of Wnt, BMP, and FGF signaling pathways in the maintenance of human DP properties [10]. According to the above, to identify the best conditions for DP cell maintaining prior to inclusion into aggregates, we incubated them with the following soluble factors and molecules: BMP6, VD3, VPA, Wnt3a, and Wnt5a. We used Dkk1 as a negative control to compare with Wnts. FGF20 was included as the factor promoting DP cell aggregation during HF development [36].

We analyzed the expression of DP-specific markers, namely, ALP and versican. Basing on immunocytochemical analysis, the most significant upregulation was recorded in cultures with the addition of BMP6, VD3, and VPA (Figure 6). Therefore, we suggested that these factors would be the most promising in terms of aggregate generation.

Further, we evaluated the influence of proteoglycans (aggrecan, biglycan, and fibronectin), glycosaminoglycan CS, and collagen I on DP marker expression. Furthermore, we tested matrigel as a basal lamina substitute and HA, since it is widespread in the embryonic skin where multiple events of HF morphogenesis occur [37]. We did not observe the upregulation of ALP or versican expression in any cases (Figure 7).

Since proliferation level is important for proper HF morphogenesis, we analyzed the influence of soluble factors and ECM molecules on the proliferation of DP cells in 

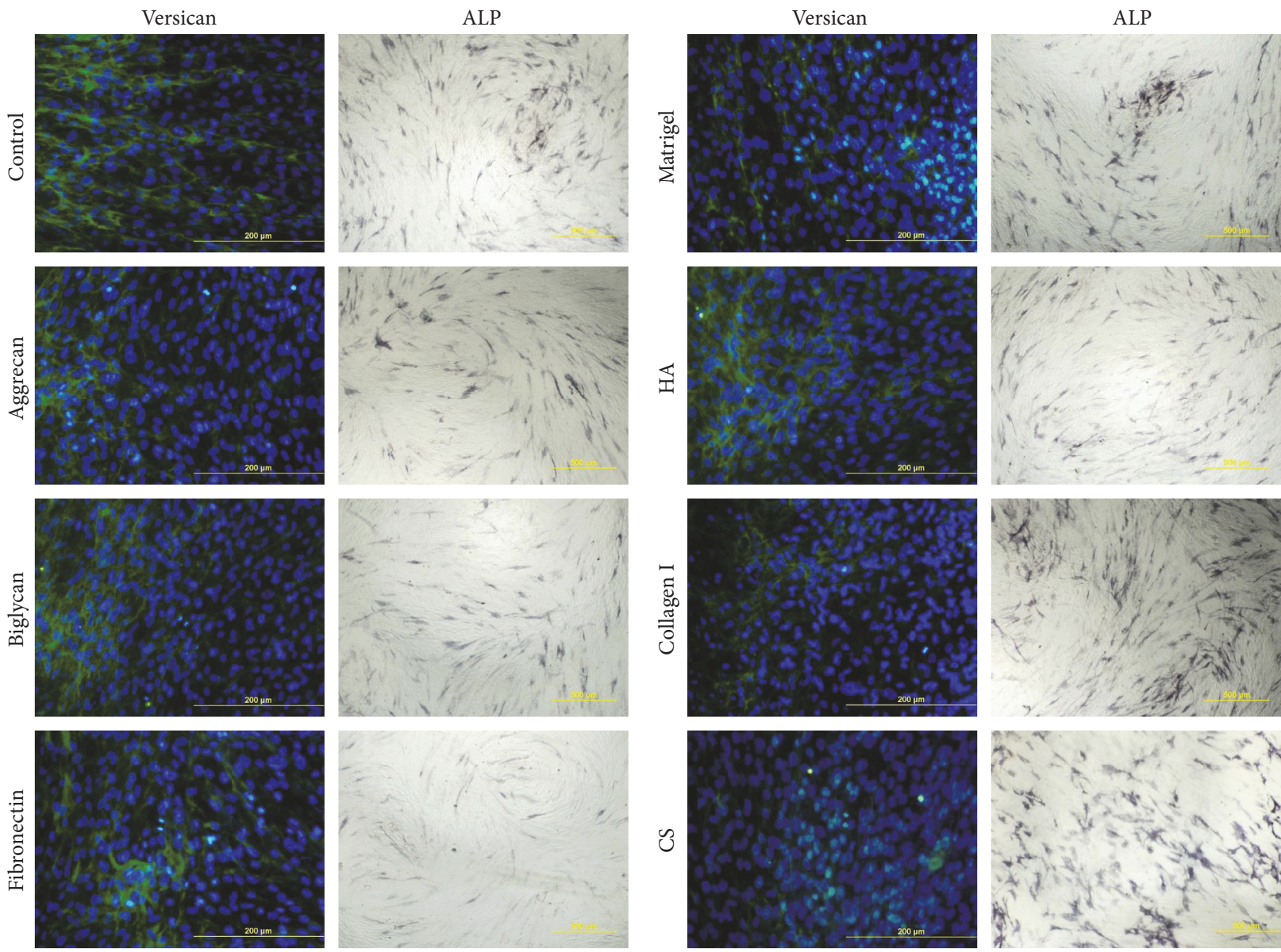

Figure 7: Versican and ALP expression in DP cells cultured on ECM compounds. Versican staining was analyzed using fluorescent microscopy; scale bare $200 \mu \mathrm{m}$. ALP staining was analyzed using bright field microscopy; scale bare $500 \mu \mathrm{m}$. HA: hyaluronic acid; CS: chondroitin sulphate.

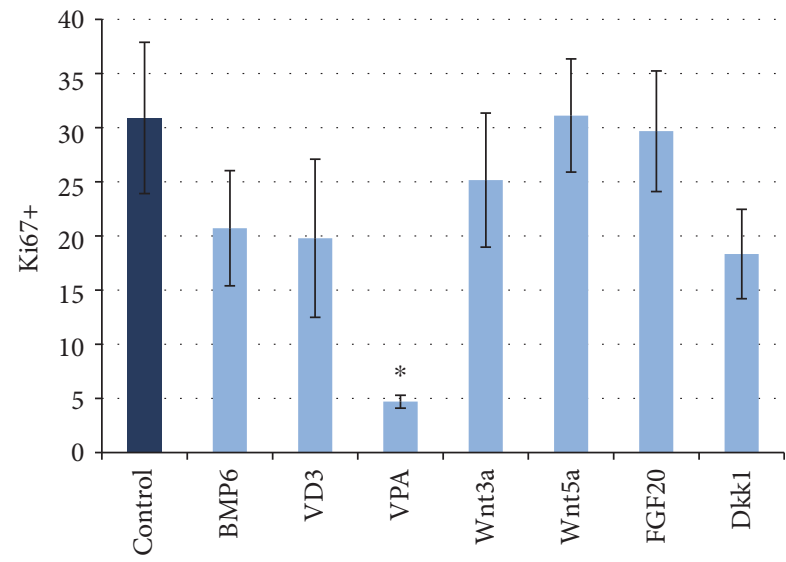

(a)

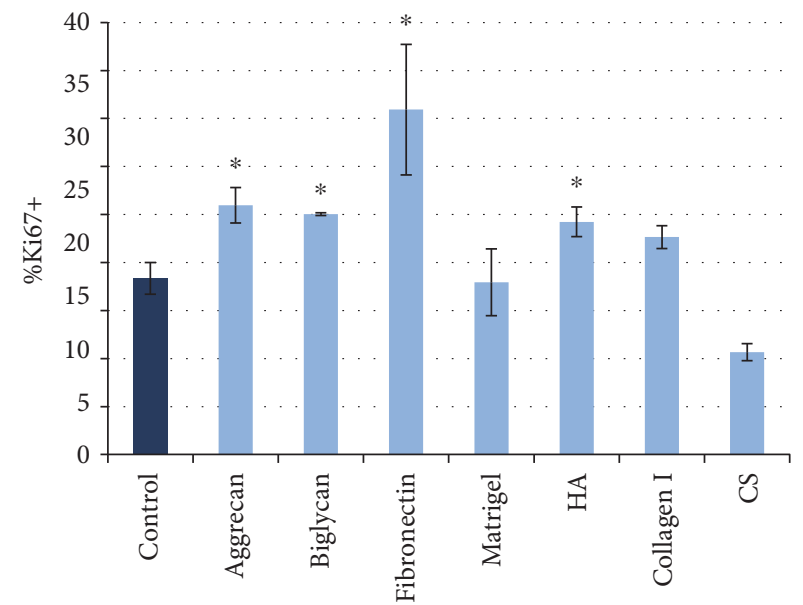

(b)

FIGURE 8: (a) The rate of Ki67 $7^{+}$nuclei in DP cell culture in the presence of soluble factors. (b) The rate of Ki67 $7^{+}$nuclei in DP cell culture in the presence of ECM components. ${ }^{*} p<0.05$, Mann-Whitney $U$ test. HA: hyaluronic acid; CS: chondroitin sulphate.

monolayer culture to select the most promising for aggregate generation. Soluble factors did not affect DP cell proliferation except VPA, which suppress cell division (Figure 8(a)). We found that proteoglycans and HA upregulated the rate of proliferative cells, while none of ECM components under investigation retarded proliferation (Figure 8(b)). 


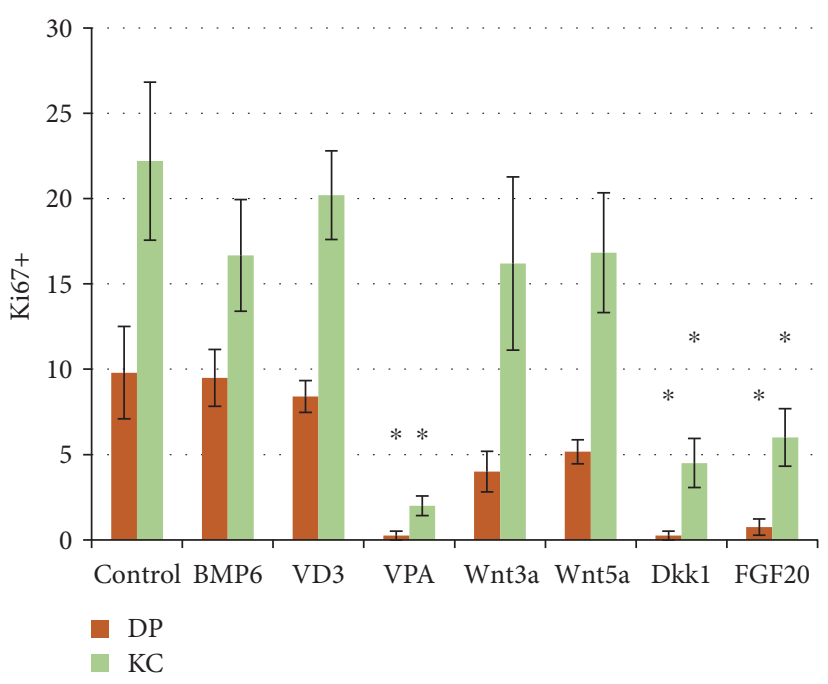

(a)

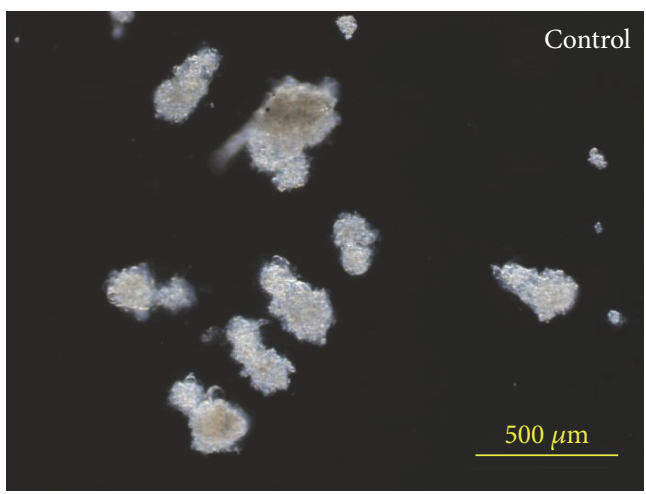

(d)
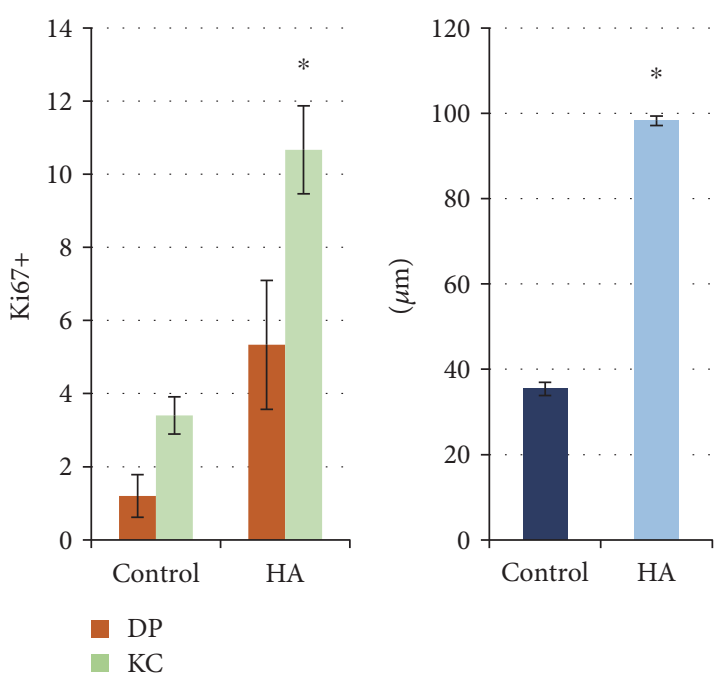

(b)

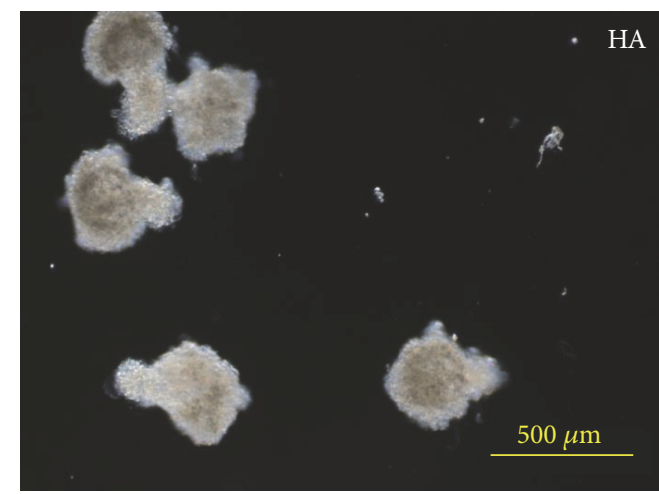

(e)

FIgURE 9: (a) The number of Ki67 $7^{+}$nuclei of DP cells and KCs in mixed aggregates per one aggregate, obtained in the presence of growth factors. (b) The number of Ki67 $7^{+}$nuclei of DP cells and KCs in mixed aggregates per one aggregate, obtained in the presence of HA. (c) The size of mixed aggregates in the presence of HA. The appearance of aggregate obtained (d) in control cultures and (e) in the presence of HA; bright field microscopy, ${ }^{*} p<0.05$, Mann-Whitney $U$ test.

In native niche, DP cells are supported by soluble factors produced by epithelial stem cells from the bulge and hair germ regions. Both types of WNT pathways operate the HF development and cycling. VPA has been shown to be a prospective WNT signaling activator and stimulator of HF regrowth $[38,39]$. BMP signaling molecules regulate the differentiation processes during the HF cycling and development [11]. Therefore, our results concerning the expression of DP markers are in agreement with previous studies. The absence of proliferation stimulation could be a result of a specific status of adult DP cells with high hair-inducing abilities [40].

DP cells produce a wide diversity of ECM compounds, including proteoglycans and collagens. The composition and contents are changed during the hair cycle; this suggests the pivotal role of ECM in the modulation of growth factor signaling and regulations of differentiation and proliferation processes [41-43]. It has been shown that canine DP cells upregulate the expression of $\mathrm{Wnt} / \beta$ catenin pathway members on laminin substrate [41].

Our results demonstrated that ECM molecules do not have an impact in human DP hair-inducing abilities recovery but influence cell proliferation. HA supports DP cell proliferation and allows the clonal growth of these cells in $3 \mathrm{D}$ environment [44]. It is also suitable for other mesenchymal cell types $[45,46]$. In vitro, several ECM compounds regulate the processes of DP cell aggregation [47-49].

\subsection{Impact of Soluble Factors and ECM Components on} Aggregate Formation and Development. As DP cell-specific marker expression strongly correlates with their hairinducing abilities, we suggested BMP6, VD3, and VPA to be promising agents for promoting aggregate development.

All of the substances studied were added to cell suspension in the course of aggregate generation. In our hands, we did not observe any stimulation effect on cell proliferation inside aggregates neither from BMP6, VD3, and VPA nor from other substances. Moreover, VPA and FGF20 demonstrated the inhibitory effect (Figure 9(a)).

Further, we created mixed aggregates in the presence of ECM molecules previously tested in monolayer culture. Surprisingly, all the compounds prevented the aggregate formation except HA and chondroitin sulphate. HA addition 
resulted in the upregulation of KCs and DP cell proliferation (Figure 9(b)) and increased the size of aggregates (Figures 9(c), 9(d), and 9(e)) while addition of chondroitin sulphate produced no effect on the parameters of the aggregates (data not shown). According to our results in monolayer culture, VPA suppresses cell proliferation irrespectively of culture conditions, while FGF20 and Dkk1 decrease the number of Ki67-positive cells only in 3D culture with KCs. These revealed several key features about epithelialmesenchymal interactions in mixed aggregates: stimulation of DP hair-inducing abilities is not enough to upregulate $\mathrm{KC}$ proliferation. The observations indicate that DP cells in the monolayer respond differently as compared to the same cells in mixed aggregates, where they are involved in epithelial-mesenchymal interactions. It could be suggested that 3D environment has an additional impact on DP cells themselves inducing the recovery of their intrinsic features as it was shown earlier [9]. It may be speculated that DP cells in $3 \mathrm{D}$ conditions have quite different properties as compared to those in the monolayer culture, and shifting them into aggregates has a prevailing effect on their behavior. Consequently, soluble factors did not produce an expected additional effect in terms of hair germ development. Significant inhibition of cell proliferation with Dkk1 indicates that Wnt activation is indispensable for proper aggregate arrangement and initial steps of in vitro folliculogenesis. Inefficiency of Wnt members to promote HF morphogenesis demonstrates that the Wnt pathway in aggregates is activated basically by intercellular contacts rather than paracrine signaling.

HA stimulates Wnt pathway activation in mesenchymal stem cells [45]. Apparently, this activation is carried out by cell contacts; this confirms our hypothesis about major role signaling via cell contacts rather than paracrine factors in aggregates. Therefore, HA may be further used for the establishment of proper cell-cell contacts and signaling in the course of HF in vitro development. Other ECM molecules did not facilitate aggregate formation that may indicate their secondary appearance inside native DP in the process of condensation in fetal skin.

\section{Conclusion}

In conclusion, the long-term goal of our investigation is to develop an easily obtainable model system that simulates human HF germ in culture, which could be useful for HF biology research and for clinical applications, providing the suitable system for drug testing and prospective field in HF reconstruction. The hair germ-like organoid developed in this study allows the search for niche factors maintaining HF morphogenesis.

\section{Conflicts of Interest}

The authors declare that they have no competing interests.

\section{Acknowledgments}

The work was funded by the Russian Science Foundation (Project no. 16-14-00204).

\section{References}

[1] S. C. Chueh, S. J. Lin, C. C. Chen et al., "Therapeutic strategy for hair regeneration: hair cycle activation, niche environment modulation, wound-induced follicle neogenesis, and stem cell engineering," Expert Opinion on Biological Therapy, vol. 13, no. 3, pp. 377-391, 2013.

[2] J. Lee and T. Tumbar, "Hairy tale of signaling in hair follicle development and cycling," Seminars in Cell \& Developmental Biology, vol. 23, no. 8, pp. 906-916, 2012.

[3] R. Sennett and M. Rendl, "Mesenchymal-epithelial interactions during hair follicle morphogenesis and cycling," Seminars in Cell \& Developmental Biology, vol. 23, no. 8, pp. 917-927, 2012.

[4] V. V. Terskikh, A. V. Vasiliev, and E. A. Vorotelyak, "Label retaining cells and cutaneous stem cells," Stem Cell Reviews and Reports, vol. 8, no. 2, pp. 414-425, 2012.

[5] Z. B. Mokos and E. L. Mosler, "Advances in a rapidly emerging field of hair follicle stem cell research," Collegium Antropologicum, vol. 38, no. 1, pp. 373-378, 2014.

[6] R. F. Oliver, "The induction of hair follicle formation in the adult hooded rat by vibrissa dermal papillae," Journal of Embryology and Experimental Morphology, vol. 23, no. 1, pp. 219-236, 1970.

[7] C. A. Jahoda, K. A. Horne, and R. F. Oliver, "Induction of hair growth by implantation of cultured dermal papilla cells," Nature, vol. 311, no. 5986, pp. 560-562, 1984.

[8] M. Inamatsu, T. Matsuzaki, H. Iwanari, and K. Yoshizato, "Establishment of rat dermal papilla cell lines that sustain the potency to induce hair follicles from afollicular skin," The Journal of Investigative Dermatology, vol. 111, no. 5, pp. 767-775, 1998.

[9] C. A. Higgins, J. C. Chen, J. E. Cerise, C. A. B. Jahoda, and A. M. Christiano, "Microenvironmental reprogramming by three-dimensional culture enables dermal papilla cells to induce de novo human hair-follicle growth," Proceedings of the National Academy of Sciences, vol. 110, no. 49, pp. 19679-19688, 2013.

[10] M. Ohyama, T. Kobayashi, T. Sasaki, A. Shimizu, and M. Amagai, "Restoration of the intrinsic properties of human dermal papilla in vitro," Journal of Cell Science, vol. 125, no. 17, pp. 4114-4125, 2012.

[11] M. Rendl, L. Polak, and E. Fuchs, "BMP signaling in dermal papilla cells is required for their hair follicle-inductive properties," Genes \& Development, vol. 22, no. 4, pp. 543557, 2008.

[12] N. Aoi, K. Inoue, T. Chikanishi et al., " $1 \alpha, 25$-dihydroxyvitamin D3 modulates the hair-inductive capacity of dermal papilla cells: therapeutic potential for hair regeneration," Stem Cells Translational Medicine, vol. 1, no. 8, pp. 615626, 2012.

[13] J. Kishimoto, R. E. Burgeson, and B. A. Morgan, "Wnt signaling maintains the hair inducing activity of the dermal papilla," Genes \& Development, vol. 14, no. 10, pp. 1181-1185, 2000.

[14] V. Greco, T. Chen, M. Rendl et al., "A two-step mechanism for stem cell activation during hair regeneration," Cell Stem Cell, vol. 4, pp. 155-169, 2009.

[15] M. Feng, G. Yang, and J. Wu, "Versican targeting by RNA interference suppresses aggregative growth of dermal papilla cells," Clinical and Experimental Dermatology, vol. 36, no. 1, pp. 77-84, 2011. 
[16] B. Havlickova, T. Bíró, A. Mescalchin, P. Arenberger, and R. Paus, "Towards optimization of an organotypic assay system that imitates human hair follicle-like epithelial-mesenchymal interactions," The British Journal of Dermatology, vol. 151, no. 4, pp. 753-765, 2004.

[17] B. Havlickova, T. Bíró, A. Mescalchin et al., "A human folliculoid microsphere assay for exploring epithelial-mesenchymal interactions in the human hair follicle," The Journal of Investigative Dermatology, vol. 129, no. 4, pp. 972-983, 2009.

[18] J. J. Wu, R. Q. Liu, Y. G. Lu, T. Y. Zhu, B. Cheng, and X. Men, "Enzyme digestion to isolate and culture human scalp dermal papilla cells: a more efficient method," Archives of Dermatological Research, vol. 297, no. 2, pp. 60-67, 2005.

[19] E. S. Chermnykh, E. A. Vorotelyak, K. Y. Gnedeva et al., "Dermal papilla cells induce keratinocyte tubulogenesis in culture," Histochemistry and Cell Biology, vol. 133, no. 5, pp. 567-576, 2010.

[20] D. L. Gay, C. C. Yang, M. V. Plikus et al., “CD133 expression correlates with membrane beta-catenin and E-cadherin loss from human hair follicle placodes during morphogenesis," The Journal of Investigative Dermatology, vol. 135, no. 1, pp. 45-55, 2015.

[21] L. Samuelov, E. Sprecher, D. Tsuruta, T. Bíró, J. E. Kloepper, and R. Paus, "P-cadherin regulates human hair growth and cycling via canonical Wnt signaling and transforming growth factor- $\beta 2$," The Journal of Investigative Dermatology, vol. 132, no. 10, pp. 2332-2341, 2012.

[22] M. Inamatsu, T. Tochio, A. Makabe et al., "Embryonic dermal condensation and adult dermal papilla induce hair follicles in adult glabrous epidermis through different mechanisms," Development, Growth \& Differentiation, vol. 48, no. 2, pp. 73-86, 2006.

[23] Y. Zheng, X. Du, W. Wang, M. Boucher, S. Parimoo, and K. Stenn, "Organogenesis from dissociated cells: generation of mature cycling hair follicles from skin-derived cells," The Journal of Investigative Dermatology, vol. 124, no. 5, pp. 867-876, 2005.

[24] Y. Zheng, A. Nace, W. Chen et al., "Mature hair follicles generated from dissociated cells: a universal mechanism of folliculoneogenesis," Developmental Dynamics, vol. 239, no. 10, pp. 2619-2626, 2010.

[25] J. Qiao, A. Turetsky, P. Kemp, and J. Teumer, "Hair morphogenesis in vitro: formation of hair structures suitable for implantation," Regenerative Medicine, vol. 3, no. 5, pp. 683692, 2008.

[26] S. Ihara, M. Watanabe, E. Nagao, and N. Shioya, "Formation of hair follicles from a single-cell suspension of embryonic rat skin by a two-step procedure in vitro," Cell and Tissue Research, vol. 266, no. 1, pp. 65-73, 1991.

[27] A. Takeda, S. Matsuhashi, N. Shioya, and S. Ihara, "Histodifferentiation of hair follicles in grafting of cell aggregates obtained by rotation culture of embryonic rat skin," Scandinavian Journal of Plastic and Reconstructive Surgery and Hand Surgery, vol. 32, no. 4, pp. 359-364, 1998.

[28] K. Nakao, R. Morita, Y. Saji et al., "The development of a bioengineered organ germ method," Nature Methods, vol. 4, no. 3, pp. 227-230, 2007.

[29] M. Oshima, M. Mizuno, A. Imamura et al., "Functional tooth regeneration using a bioengineered tooth unit as a mature organ replacement regenerative therapy," PLoS One, vol. 6, no. 7 , article e21531, 2011.
[30] N. Jiang, J. Zhou, M. Chen et al., "Postnatal epithelium and mesenchyme stem/progenitor cells in bioengineered amelogenesis and dentinogenesis," Biomaterials, vol. 35, no. 7, pp. 2172-2180, 2014.

[31] Q. Tan, K. M. Choi, D. Sicard, and D. J. Tschumperlin, "Human airway organoid engineering as a step toward lung regeneration and disease modeling," Biomaterials, vol. 113, pp. 118-132, 2017.

[32] A. E. Cerchiari, K. E. Samy, M. E. Todhunter et al., "Probing the luminal microenvironment of reconstituted epithelial microtissues," Scientific Reports, vol. 6, article 33148, 2016.

[33] C. Wei, M. Larsen, M. P. Hoffman, and K. M. Yamada, "Self-organization and branching morphogenesis of primary salivary epithelial cells," Tissue Engineering, vol. 13, no. 4, pp. 721-735, 2007.

[34] C. M. Yen, C. C. Chan, and S. J. Lin, "High-throughput reconstitution of epithelial-mesenchymal interaction in folliculoid microtissues by biomaterial-facilitated self-assembly of dissociated heterotypic adult cells," Biomaterials, vol. 31, no. 15, pp. 4341-4352, 2010.

[35] T. Kobayashi, A. Fujisawa, M. Amagai, T. Iwasaki, and M. Ohyama, "Molecular biological and immunohistological characterization of canine dermal papilla cells and the evaluation of culture conditions," Veterinary Dermatology, vol. 22, no. 5, pp. 414-422, 2011

[36] S. H. Huh, K. Närhi, P. H. Lindfors et al., "Fgf20 governs formation of primary and secondary dermal condensations in developing hair follicles," Genes \& Development, vol. 27, no. 4, pp. 450-458, 2013.

[37] U. M. Agren, M. Tammi, M. Ryynänen, and R. Tammi, "Developmentally programmed expression of hyaluronan in human skin and its appendages," The Journal of Investigative Dermatology, vol. 109, no. 2, pp. 219-224, 1997.

[38] S. J. Jo, S. J. Choi, S. Y. Yoon et al., "Valproic acid promotes human hair growth in vitro culture model," Journal of Dermatological Science, vol. 72, no. 1, pp. 16-24, 2013.

[39] S. H. Lee, J. Yoon, S. H. Shin et al., "Valproic acid induces hair regeneration in murine model and activates alkaline phosphatase activity in human dermal papilla cells," PLoS One, vol. 7, no. 4, article e34152, 2012.

[40] C. A. Higgins, G. D. Richardson, D. Ferdinando, G. E. Westgate, and C. A. Jahoda, "Modelling the hair follicle dermal papilla using spheroid cell cultures," Experimental Dermatology, vol. 19, no. 6, pp. 546-548, 2010.

[41] E. D. Kaplan and K. A. Holbrook, "Dynamic expression patterns of tenascin, proteoglycans, and cell adhesion molecules during human hair follicle morphogenesis," Developmental Dynamics, vol. 199, no. 2, pp. 141-155, 1994.

[42] S. Malgouries, S. Thibaut, and B. A. Bernard, "Proteoglycan expression patterns in human hair follicle," The British Journal of Dermatology, vol. 158, no. 2, pp. 234-242, 2008.

[43] K. Y. Tsang, M. C. Cheung, D. Chan, and K. S. Cheah, "The developmental roles of the extracellular matrix: beyond structure to regulation," Cell and Tissue Research, vol. 339, no. 1, pp. 93-110, 2010.

[44] R. R. Driskell, V. R. Juneja, J. T. Connelly, K. Kretzschmar, D. W. Tan, and F. M. Watt, "Clonal growth of dermal papilla cells in hydrogels reveals intrinsic differences between Sox2positive and -negative cells in vitro and in vivo," The Journal of Investigative Dermatology, vol. 132, no. 4, pp. 10841093, 2012. 
[45] R. M. Liu, R. G. Sun, L. T. Zhang et al., "Hyaluronic acid enhances proliferation of human amniotic mesenchymal stem cells through activation of Wnt/ $\beta$-catenin signaling pathway," Experimental Cell Research, vol. 345, no. 2, pp. 218-229, 2016.

[46] K. Gwon, E. Kim, and G. Tae, "Heparin-hyaluronic acid hydrogel for efficient cellular activities of 3D encapsulated adipose derived stem cells," Acta Biomaterialia, vol. 49, pp. 284-295, 2016.

[47] B. Rocha-Azevedo and F. Grinnell, "Fibroblast morphogenesis on 3D collagen matrices: the balance between cell clustering and cell migration," Experimental Cell Research, vol. 319, no. 16, pp. 2440-2446, 2013.

[48] Y. Yang, Y. Li, Y. Wang et al., "Versican gene: regulation by the $\beta$-catenin signaling pathway plays a significant role in dermal papilla cell aggregative growth," Journal of Dermatological Science, vol. 68, no. 3, pp. 157-163, 2012.

[49] T. H. Young, H. R. Tu, C. C. Chan et al., "The enhancement of dermal papilla cell aggregation by extracellular matrix proteins through effects on cell-substratum adhesivity and cell motility," Biomaterials, vol. 30, no. 28, pp. 5031-5040, 2009. 

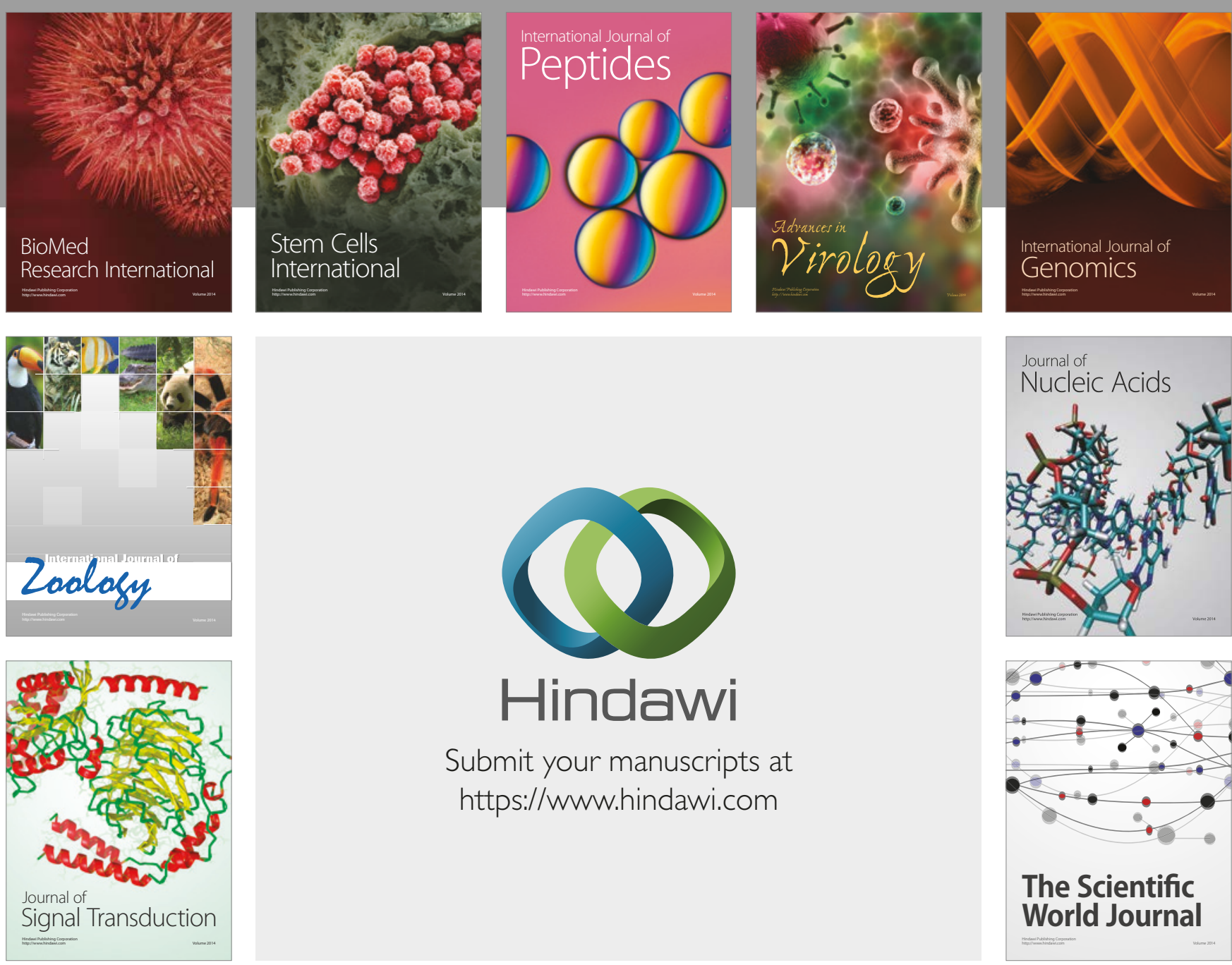

Submit your manuscripts at

https://www.hindawi.com
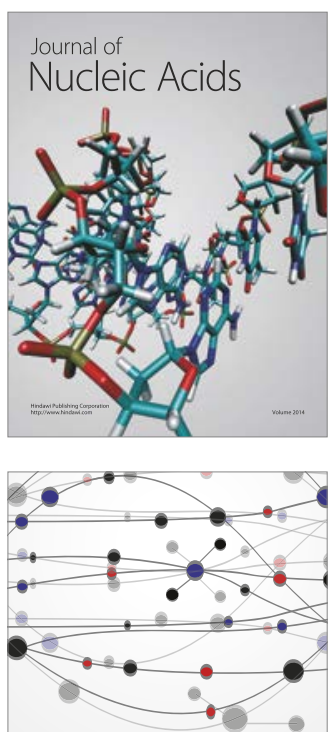

The Scientific World Journal

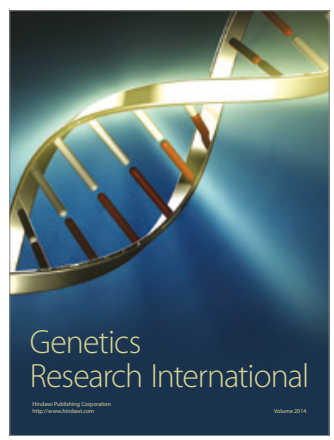

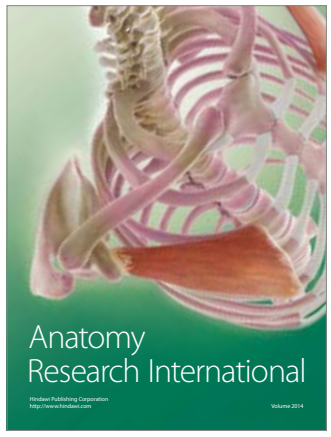

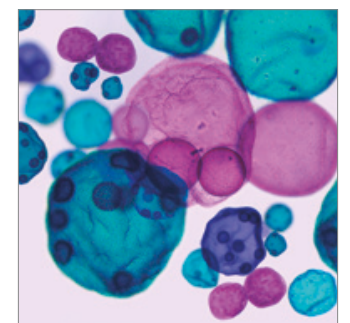

International Journal of Microbiology
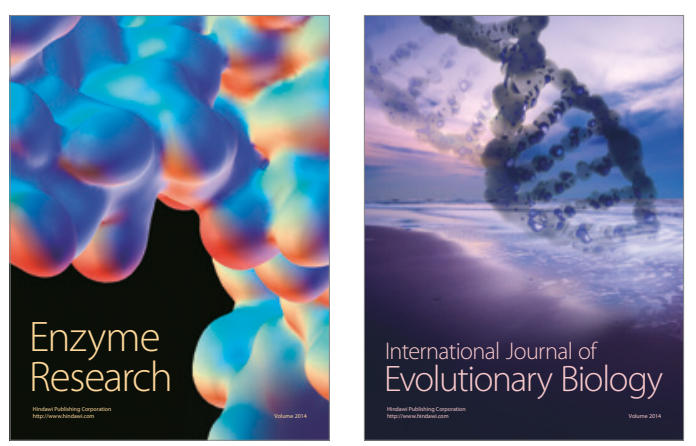
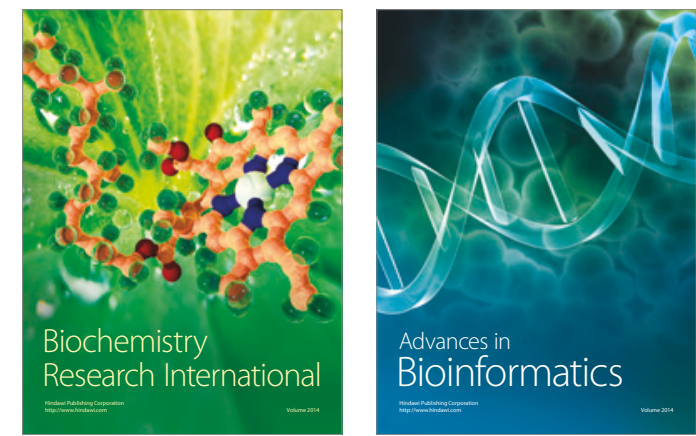

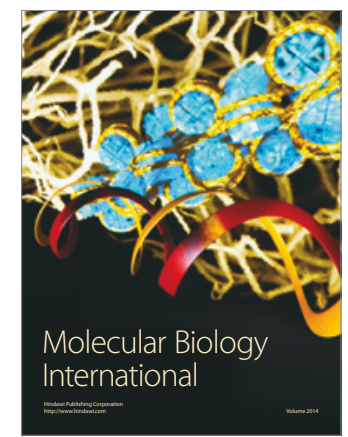

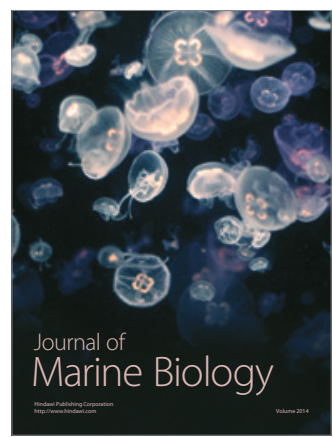

